\title{
Anti-HIV 1/2 Reaktif Saptanan Hastaların Doğrulama Test Sonuçları İle Birlikte Değerlendirilmesi
}

\author{
Evaluation of Patients with Anti-HIV 1/2 Reactivity with Confirmation Test Results
}

\author{
Hande Toptan ${ }^{1}$, Ferhat Gürkan Aslan², Engin Karakeçe ${ }^{3}$, Özlem Aydemir ${ }^{3}$, Tayfur Demiray ${ }^{3}$, \\ Mehmet Köroğlu ${ }^{1}$, Oğuz Karabay ${ }^{4}$, Mustafa Altındiş ${ }^{1}$ \\ ${ }^{1}$ Sakarya Üniversitesi Tip Fakültesi, Tibbi Mikrobiyoloji AD, Sakarya, Türkiye \\ ${ }^{2}$ Fatih Sultan Mehmet Eğitim ve Araştırma Hastanesi, Tibbi Mikrobiyoloji AD, İstanbul, Türkiye \\ ${ }^{3}$ Sakarya Üniversitesi Eğitim ve Araştırma Hastanesi, Tibbi Mikrobiyoloji AD, Sakarya, Türkiye \\ ${ }^{4}$ Sakarya Üniversitesi Tip Fakültesi, Enfeksiyon Hastalıkları ve Klinik Mikrobiyoloji AD, Sakarya, Türkiye
}

ORCID

Hande Toptan: https://orcid.org/0000-0001-6893-8490

Ferhat Gürkan Aslan: https://orcid.org/0000-0001-8394-1962

Engin Karakeçe: https://orcid.org/0000-0003-1941-621X

Özlem Aydemir: https://orcid.org/0000-0003-4533-6934
Tayfur Demiray: https://orcid.org/0000-0003-1161-4684 Mehmet Köroğlu: https://orcid.org/ 0000-0001-8101-1104

Oğuz Karabay: https://orcid.org/0000-0003-1514-1685

Mustafa Altındiș: https://orcid.org/0000-0003-0411-9669

Yazışma Adresi / Correspondence:

Hande Toptan

Sakarya Üniversitesi Eğitim ve Araştırma Hastanesi, Tibbi Mikrobiyoloji Laboratuvarı, Sakarya

Tel: +902644445400 E-mail: hande_cakar@hotmail.com

Geliş Tarihi / Received : 12-03-2019 Kabul Tarihi / Accepted : 18-04-2019 Yayın Tarihi / Online Published: 30-04-2019

Toptan H., Aslan FG., Karakeçe E., Aydemir Ö., Demiray T., Köroğlu M., Karabay O., Altındiş M. Anti-HIV 1/2 Reaktif Saptanan Hastaların Doğrulama Test Sonuçları İle Birlikte Değerlendirilmesi

J Biotechnol and Strategic Health Res. 2019;3(1):27-32 DOI: 10.34084/bshr.551035

Öz

Amaç HIV enfeksiyonu tanısında ülkemizde yaygın kullanılan algoritma; mikro ELISA veya türevi bir yöntemle yapılan tarama sonrasında reaktif bulunan örneklerin referans merkezde doğrulanması șeklindedir. Çalışmamızda yeni tanı HIV hastalarının demografik verileriyle ELISA/doğrulama test sonuçlarının irdelenmesi ve ülkemiz veri sistemine katkı sağlanması amaçlanmıștır.

Gereç ve Ocak 2014 - Aralık 2018 tarihleri arasında HIV taranması amacıyla gönderilen örnekler Sakarya Üniversitesi Eğitim ve Araștırma Hastanesi Mikrobiyoloji Laboratuvarında

Yöntemler Anti-HIV 1/2 Makro ve Mikro ELISA yöntemleri ile çalıșılmıștır. Reaktif saptanan örnekler doğrulama için referans laboratuvara gönderilmiștir. Sonuçlar retrospektif olarak taranarak hastaların yaşı, cinsiyeti, örneğin gönderildiği klinik gibi verileri kaydedilmiştir.

Bulgular Çalışlan serum örneğinde anti-HIV 1/2 testi reaktif saptanan 254 hastanın; 192’si (\%75.5) erkek, 62’si (\%24.4) kadın hastadır. En çok reaktif saptanan yaş grubu 26-35 olarak saptanmıștır. HIV 1/2 antikor ayırt edici hızlı test kullanılarak yapılan doğrulama sonucunda pozitif olarak belirlenen 173 örneğin 155’i (\%89.6) erkek, 18’i (\%10.4) kadın hastadır. Anti HIV 1/2 testi reaktif olup doğrulama sonucu negatif gelen 78 hastanın 42'sini (\%53.8) kadınlar olusturmaktadır. Doğrulama sonucu pozitif olarak belirlenen ELISA reaktif sonuçların tamamı 5 S/Co’ten büyük olarak saptanmıștır. Yanlıs reaktif saptanan en yüksek mikro ELISA değeri 13.3 S/Co iken; gerçek reaktif en düşük mikro ELISA değeri $5.29 \mathrm{~S} /$ Co olarak belirlenmiștir.

Sonuç HIV pozitifliğinin daha sık görüldüğü cinsiyet erkek (\%75.5); yaş grubu 26-35 olarak belirlenmiștir. Gerçek pozitif hastaların \%10.4’ünün; yalancı pozitif hastalarınsa \%53.8'inin kadın olması dikkat cekicidir. Bu durum yalancı pozitifliğe sebep durumların kadınlarda sık görülmesiyle açılanabilir. Test sonuçları 78 örnekte uyumsuz bulunmuștur. Eșik değerin; $1.0 \mathrm{~S} / \mathrm{Co}$ yerine $5.0 \mathrm{~S} /$ Co olarak belirlenmesi durumda hiçbir pozitif hasta gözden kaçmayacakken doğrulamaya gereksiz yere gönderilmis örnek, 78 yerine 14 olabilecektir. Ancak bu değerin altında da gerçek pozitiflikler olabileceğinden (hastalı̆ı̆n başlangıç evreleri gibi) ve tarama testi olduğundan dolayı mevcut haliyle uygulamaya devam edilmektedir.

Anahtar ELISA, HIV, Yalancı pozitiflik, Gerçek pozitiflik

Kelimeler

Abstract

Objective The widely used algorithm in the diagnosis of HIV infection in our country is after screening the samples by micro-ELISA, sending them to reference laboratory for confirmation. The aim of this study was to evaluate the demographic data and the ELISA/confirmation test results of newly diagnosed HIV patients and to contribute to the data in our countr.

Materials and Between January 2014 and December 2018 Anti-HIV 1/2 Macro and Micro ELISA tests were studied in the Microbiology Laboratory of Sakarya University Training and Research Hospital.

Methods Reactive samples were sent to the reference laboratory. HIV $1 / 2$ Confirmatory Assay was used for confirmation. The results were scanned retrospectively and the data were recorded including the age and gender of the patients, and the clinic where they were sent.

Results Of 254 patients with anti-HIV 1/2 reactivity; 192 (75.5\%) were male and 62 (24.4\%) were female. The most reactivity detected age group was 26-35. Of the 173 confirmed results, 155 (89.6\%) were male and $18(10.4 \%)$ were female. Of the 78 patients with incompatible results, $42(53.8 \%)$ were female. All of the reactive results confirmed as positive were found to be greater than $5 \mathrm{~S}$ Co. The highest false reactivity value was $13.3 \mathrm{~S} / \mathrm{Co}$; the lowest true reactivity value was $5.29 \mathrm{~S} / \mathrm{Co}$.

Conclusion The gender that HIV positivity was more frequent was male and the age group was 26-35. False positivity was higher in females. It can be explained by the conditions causing false positivity are more frequently associated with women. Test results were found incompatible in 78 samples. If the cut-off value was determined to be $5.0 \mathrm{~S} / \mathrm{Co}$ instead of $1.0 \mathrm{~S} / \mathrm{Co}$, no positive patient would be overlooked, but the sample sent unnecessarily to confirmation would be 14 instead of 78. However, under this value there may be true positivities (such as the initial stages of disease) and it's a screening test so its current cut-off is still in use.

Keywords ELISA, HIV, False positivity, True positivity 


\section{GIIRIŞ}

HIV enfeksiyonu 1981 yılında ortaya çıkışının ardından hızla yayılmış ve tüm dünyayı ilgilendiren bir sorun haline gelmiştir. Dünya Sağlık Örgütünün (DSÖ) 2017 yılı sonu yayınladığ HIV ile enfekte olarak yaşayan 36.9 milyon; HIV ile ilişkili nedenlerden hayatını kaybeden 940 bin insan bulunmaktadır. HIV ile enfekte insanların yapılan tahminleme modellerine göre 18.2 milyonu kadın, 16.9 milyonu erkek, 1.8 milyonu çocuk hastalardan oluşmaktadır ${ }^{1}$.

Türkiye'de ise ilk vakanın görüldüğü 1985 yılından bu yana (31 Aralık 2017 itibariyle) 17.884 vaka bildirilmiştir. Vakaların yaklaşık \%80'ini erkek, \%20'sini kadınlar oluşturmaktadır².

Birleşmiş Milletler HIV/AIDS Ortak Programının (Joint United Nations Programme on HIV/AIDS - UNAIDS) HIV epidemisini kontrol altına almak ve 2030 yılına kadar elimine etmek için 2020 yılına kadar ulaşmayı hedeflediği bir takım hedefler olup, bunlar 90-90-90 hedefleri olarak bilinmektedir. Bu hedefler; HIV ile enfekte yaşayan tüm insanların \% 90’ının tanı alarak HIV taşıyıcısı olduklarının bilincinde olması, HIV tanısı alan tüm kişilerin \% 90’ının kesintisiz antiretroviral tedavi altına alınması, antiretroviral tedavi alan tüm insanların \% 90’ında viral baskılama gerçekleşmesi şeklindedir ${ }^{3}$.

Bazı Batı Avrupa ve Amerika ülkeleri bu hedeflere yaklaşmış ya da hedefi tutturmuşken; Doğu Avrupa ve Merkez Asya ile ülkemizin de içinde bulunduğu Orta Avrupa bu hedeflerin gerisinde kalmıştır ${ }^{4}$. Ayrıca UNAIDS platformunda ülkemizin epidemiyolojik verilerinin bulunmaması da ülkemiz adına bir eksiklik olarak karşımıza çıkmakta ve bu alanda yapılacak çalışmalara ağırlık vermemiz gerektiğini göstermektedir.

Birleşmiş Milletler Genel Kurulunun 2011 yılında aldığı kararlara göre, 2012 yılından itibaren tüm üye devletler HIV sürveyans sistemlerini değerlendirmeli ve geliştirme- lidir, bu sayede toplanan veriler ulusal veriyi sağlayacak ve uluslararası epidemiyolojiye katkıda bulunacaktır ${ }^{5}$. Ancak bugün hala Sağlık Bakanlığı, HIV/AIDS vakaları için güvenilir ve verimli bir veri toplama sistemine sahip değildir. Bulaş yolu başta olmak üzere HIV verilerinin sağlıklı bir şekilde elde edilmesi, uygun önlemlerin alınması ve yeni vakaların engellenmesini sağlayarak UNAIDS'in 90-90-90 hedefine ülkemizi yaklaştırabilecektir.

Bu çalışmada yeni tanı almış HIV ile enfekte hastaların demografik verileriyle ELISA ve doğrulama test sonuçlarının irdelenmesi amaçlanmıştır. Bu ve buna benzer çalışmalardan elde edilecek verilerle ülkemiz veri sisteminin oluşturulmasina destek olunacak ve HIV ile enfekte bireylerin demografik verilerinin irdelenmesiyle ülkemizin HIV ile mücadele politikasına katkıda bulunulacaktır.

\section{MATERYAL ve METOD}

Çalışmamıza Sakarya Üniversitesi Eğitim ve Araştırma Hastanesi Tibbi Mikrobiyoloji Laboratuvarında Ocak 2014 - Aralık 2018 tarihleri arasında Anti HIV 1/2 Mikro ELISA (kit: Siemens, cihaz: Triturus, Grifols, İspanya) testi reaktif saptanarak doğrulama testi yapılmak üzere Halk Sağlığı Genel Müdürlüğü Mikrobiyoloji Referans Laboratuvarları ve Biyolojik Ürünler Dairesi Başkanlığı’na gönderilen 254 örnek dahil edilmiştir. Çalışma sonucu Anti HIV 1/2 testi reaktif saptanan serum örnekleri doğrulamaya gönderilmeden önce aynı kitle ve farklı bir yöntem olan Kemilüminesans Mikropartikül İmmunoassay (Chemiluminescent Microparticle Immunoassay - CMIA) (Architect I2000, Abbott, ABD) ile yeniden çalışılmıştır. Doğrulama testi olarak Geenius HIV-1/2 Supplemental Assay (Bio-Rad, Fransa) kullanılmıştır. ELISA testi için eşik değer $<1.00 \mathrm{~S} /$ Co değerine sahip olan örnekler nonreaktif; $\geq 1.00 \mathrm{~S} / \mathrm{Co}$ değerlerine sahip örnekler reaktif olarak belirlenmiştir. Hastaların yaşı, cinsiyeti, örneğin gönderildiği klinik gibi bilgiler hastane veri sisteminden retrospektif olarak derlenmiştir. 
Journal of BSHR 2019;3(1):27-32

TOPTAN, ASLAN, KARAKEÇE, AYDEMIR, DEMIRAY, KÖROĞLU, KARABAY, ALTINDIȘ. Anti-HIV 1⁄2 Reaktif Saptanan Hastaların Doğrulama Test Sonuçları İle Birlikte Değerlendirilmesi

\section{BULGULAR}

Anti HIV $1 / 2$ reaktif saptanan hastaların 192'si (\%75.5) erkek, 62'si (\%24.4) kadın hastadır. Örneklerin 137'si (\%53.9) Enfeksiyon Hastalıkları, 37'si (\%14.6) Dahili Bilimler, 36's1 (\%14.2) Cerrahi Bilimler, 18'i (\%7.1) Kadın Doğum, 12'si (\%4.7) Dermatoloji Servislerinden, 11'i (\%4.3) Kan Merkezinden, 2'si (\%0.8) AMATEM'den ve 1'i (\%0.4) Pediyatri servisinden gönderilmiştir (Şekil 1).

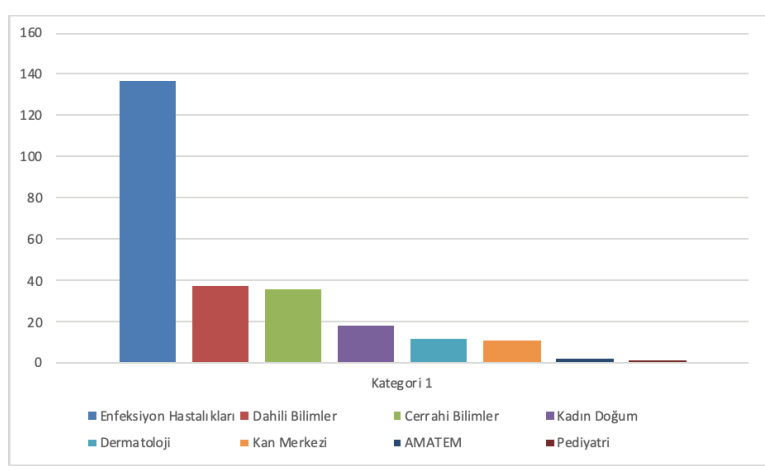

Şekil 1: Anti HIV 1/2 reaktif saptanan örneklerin gönderildiği servislere göre dağılımları

Anti HIV 1/2 reaktif saptanan hastaların yaş aralıklarına göre dağılımları Şekil 2'de sunulmuştur. En çok reaktif saptanan grup 26-35 yaş grubuyken, bunu 36-45 yaş grubu ve 17-25 yaş grubu takip etmiştir.

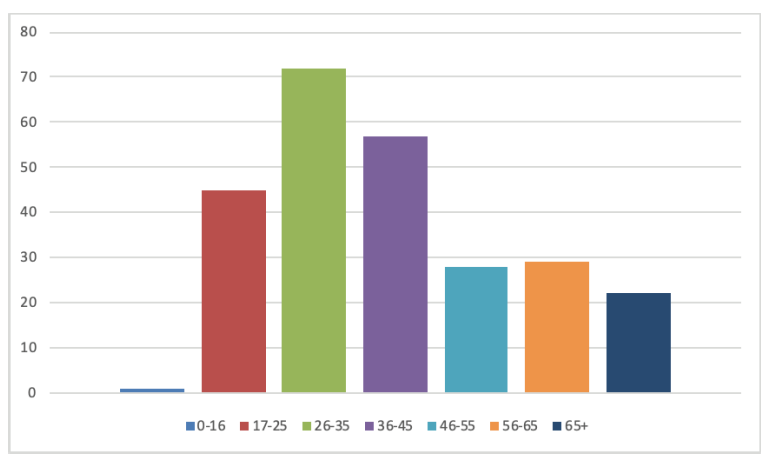

Şekil 2: Serum örnekleri Anti HIV 1/2 reaktif saptanan hastaların yaş gruplarına göre dağılımları

Reaktif saptanan 254 serum örneğinin doğrulama sonuçları incelendiğinde; 173 tanesinin pozitif, 78 tanesinin ne- gatif, 3 tanesinin indetermine olarak saptandığı görülmüştür. İndetermine sonuçlanan örneklerin 2-4 hafta sonra yapılan tekrarlarında Kadın doğum servisinden gelen bir örneğin negatif olarak saptandığı, diğer 2 örneğin ise pozitifleștiği gözlenmiştir.

Doğrulama sonucunda pozitif olarak belirlenen 173 örneğin 155’i (\%89.6) erkek, 18’i (\%10.4) kadın hastadır. Anti HIV $1 / 2$ testi reaktif olup doğrulama sonucu negatif gelen 78 hastanın 42'sini (\%53.8) kadınlar oluşturmaktadır.

Kadın doğum servisinden gönderilen 18 reaktif örneğin doğrulama sonucu sadece 2 hasta için pozitif olarak belirlenmiştir. Servislere göre doğrulama sonucu pozitif gelme oranı en yüksek klinik ise Cildiye kliniği olmuştur (\%91.7) (Şekil 3).

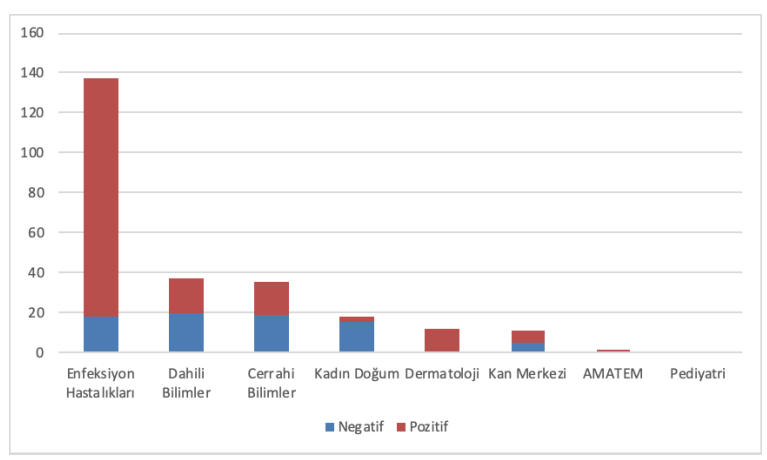

Şekil 3: Servislere göre HIV doğrulama testi sonucu pozitif gelme oranı

Doğrulama sonucu pozitif olarak belirlenen ELISA reaktif sonuçların tamamı 5 S/Co'den büyük olarak saptanmıştır. Yanlış reaktif saptanan en yüksek mikro ELISA değeri 13.3 S/Co olarak bulunurken; gerçek reaktif en düşük mikro ELISA değeri 5.29 S/Co olarak belirlenmiştir.

\section{TARTIŞMA}

Bulaşıcı hastalıklar doğaları gereği geniş kitlelere yayılma ve epidemi/pandemi yapma potansiyeli olan, toplum sağl1ğını yakından ilgilendiren durumlardandır. Ülkemizde ilk HIV pozitif olgunun 1985 yılında bildirilmesiyle başlayan süreç günden güne önemi artarak devam etmektedir. İlk 
olgunun tespiti ile aynı sene HIV/AIDS bildirimi zorunlu hastalıklar listesine alınmıştır. Bundan sadece 1 sene sonra tüm kan ve kan ürünlerinin HIV yönünden taranmasina ilişkin genelge yürürlüğe girmiştir. 1987 yılında ise kan/ organ/doku donörlerinde ve kayıtlı seks çalışanlarında serolojik testler uygulanmaya başlanmıştır ${ }^{6-8} .1993$ yılı itibariyle D-86 formları uygulamaya konmuş, 1994 yılında HIV/AIDS bildirimleri kodlu hâle gelmiştir. 1996 yılında antiretroviral tedavinin (ART) geri ödemesine başlanmıştir.

Ülkemizde ve tüm dünyada yakın zamana kadar HIV doğrulamada kullanılan test yaygın olarak Western Blot idi. Ancak duyarlılığın az, çapraz reaksiyonların fazla ve uygulamanın zahmetli olması gibi nedenlerden dolayı Hastalık Kontrol ve Önleme Merkezi (Center for Disease Control and Prevention-CDC) o zamana kadar uygulanan algoritmayı revize etti ve doğrulama testi olarak HIV $1 / 2$ antikor ayırt edici hızlı test kullanılmasını önermiştir9 ${ }^{9}$ Ülkemizde de 2017 yılı itibariyle doğrulama testi olarak Ankara Halk Sağlığı Viroloji Referans Laboratuvarı tarafından CDC tarafından önerilen HIV $1 \frac{2}{2}$ antikor ayırt edici hızlı test kullanılmaktadır.

Dünya Sağlık Örgütünün epidemiyolojik verilerine göre, 2017 yıl sonu itibariyle dünya üzerinde HIV ile enfekte olarak yaşayan 36.9 milyon; HIV ile ilişkili nedenlerden hayatını kaybeden 940 bin insan bulunmaktadır. HIV ile enfekte insanların yapılan tahminleme modellerine göre 18.2 milyonu kadın, 16.9 milyonu erkek, 1.8 milyonu çocuk hastalardan oluşmaktadır1.

Ülkemizde HIV/AIDS hala düşük düzeyde seyretmektedir. Uluslararası platformda da prevalansın düşük olduğu ülkeler arasında yer almakla birlikte gerçek sayının yapılan tahminleme modellerine göre bildirilenden çok daha fazla, yaklaşık 75255 olduğu tahmin edilmektedir ${ }^{10}$. Türkiye’de hastalığın yayılımı ve görülme sıklığı dünya ülkelerine göre düşük olmakla beraber, yıllar içinde artmaya da devam etmektedir. Turizm sektörünün ülkemizde her geçen yıl giderek gelişmesi ile birlikte ülkemize her geçen gün daha fazla sayıda turist gelmektedir Özellikle HIV/ AIDS prevalansının yüksek olduğu ülkelerden gelen turistler arasında bu hastalığa yakalanmış kişilerin olma olasılığı fazladır. Yurt dışında çalışan Türk vatandaşlarının çok sayıda olması ve giderek artması ile birlikte özellikle yurt dışında uzun süreli bulunan vatandaşlarımızın bulundukları ülkedeki hasta sayısının sıklığına bağlı olarak HIV ile enfekte olma riski artmaktadır ${ }^{11,12}$.

Türkiye'de HIV epidemisinde dikkati çeken bir başka önemli nokta da, yeni tanı alanların yaşlarının giderek düşmeye başlamış olmasıdır. Bu durum hem Sağlık Bakanlığı'nın resmi verilerinde hem de gerçek yaşam verilerinde açıkça görülmektedir. Yeni tanılarda en yüksek oran halen 25-34 yaş grubunda görülmekle birlikte, 35-44 yaş grubunun giderek azaldığı, buna karşılık 20-24 yaş grubunun arttığı dikkati çekmektedir ${ }^{13,14}$. Mevcut çalışmamız da sağlık bakanlığının verilerini doğrular niteliktedir ve Anti-HIV $1 \frac{1}{2}$ reaktivitesi en yüksek olarak 26-35 yaş grubunda saptanmışken; 17-25 yaş grubu da oldukça yüksek oranıyla 3. en yüksek yaş grubu olarak belirlenmiştir.

Gerçek pozitif hastaların \%10.4'ünün; yalancı pozitif hastalarınsa \%53.8'inin kadın olması dikkat çekicidir. Bu durum, yalancı pozitifliğe neden olan durumların (gebelik, otoimmün hastalıklar vs...) kadınlarda sık görülmesiyle açıklanabilir. Nitekim Kadın doğum servisinden gönderilen 18 reaktif örneğin 2'sinin (\%11.1); romatoloji servisinden gönderilen 3 kadın hastaya ait reaktif örneğin 1'inin (\%33.3) doğrulama sonucunun pozitif olarak belirlenmesi bu durumu destekler niteliktedir.

HIV pandemisi boyunca dünyanın birçok yerinde HIV ile enfekte olan ve/veya AIDS tanısı alan kadın sayısı artmıştır. Sahra altı Afrika'da 2001 yılı sonunda kadınlar HIV-pozitif erişkinlerin \% 55’ini oluşturmaktayken, bu oran 2002 sonunda \% 58'e yükselmiştir. HIV bulaşmış hasta popülasyonundaki bu demografik değişiklikler, HIV bulaşmış kadınlarda hastalık ilerlemesi, antiretroviral kullanım ve 
sağkalım çalışmalarında artışa yol açmıştır ${ }^{15}$. Örneğin, araştırmalar kadınların uygun antiretroviral tedaviye erişme oranının daha düşük olduğunu tespit etmiştirir ${ }^{16}$. Türkiye'de ise 2017 sonu verilerine göre HIV ile enfekte kadınlar $\% 21.8$, erkekler \%78.2 oranındadır. Bizim çalışmamızda Türkiye verilerinin de altında; \%10.4 olarak bulunmuştur. Ancak kadın/erkek oranında artış/azalışın gösterilebilmesi için daha uzun soluklu geniş çalışmalara ihtiyaç vardır.

Dermatoloji kliniği; gönderilen 12 ELISA reaktif örneğin 11'inin (\%91.6) doğrulama sonucunun pozitif olarak belirlenmesiyle en yüksek oranda gerçek reaktif örneğin gönderildiği klinik olmuştur. Bu durum HIV/AIDS'in dermatolojik bazı bulgularının olabilmesi ve/veya dermatolojinin sifiliz gibi HIV ile koenfeksiyonunu sık gördüğümüz bazı hastalıkların ilk başvurduğu klinik olması gibi nedenlerden kaynaklanmış olabilir.

ELISA ile doğrulama test sonuçları 78 örnekte uyumsuz bulunmuştur. Eşik değerinin; 1.0 yerine 5.0 olarak belirlenmesi durumunda hiçbir pozitif hasta gözden kaçmayacakken doğrulamaya gereksiz yere gönderilmiş örnek, 78 yerine 14 olabilecektir. Acar ve arkadaşlarının ${ }^{17} 72695$ kan donörü ile gerçekleştirdiği çalışmada anti HIV taramasında tekrarlayan reaktivite elde edilen ve doğrulanan eşik değeri 5,6 olarak belirlenmiştir. Ancak bu değerin altında da gerçek pozitiflikler olabileceğinden (hastalığın başlangıç evreleri gibi) ve tarama testi olduğundan dolayı mevcut haliyle uygulamaya devam edilmektedir.

Ülkemizde yeni tanı almış HIV/AIDS vakalarının bulaş yolundan tanının konulmasına, tedavi planından tedavi etkinliğinin takibine kadar tüm basamakları içerecek ve UNAIDS ve benzeri uluslararası sistemlere entegre olabilecek bir sürveyans sistemine ihtiyaç vardır. Bu ve gelecekte yapılacak sürveyans çalışmaları, bu sistemde verilerinin toplanmasına ve geliştirilmesine katkı sağlayacaktır. 
Journal of BSHR 2019;3(1):27-32

TOPTAN, ASLAN, KARAKEÇE, AYDEMIR, DEMIRAY, KÖROĞLU, KARABAY, ALTINDIȘ. Anti-HIV 1⁄2 Reaktif Saptanan Hastaların Doğrulama Test Sonuçları İle Birlikte Değerlendirilmesi

\section{Kaynaklar}

1. WHO- https://www.who.int/hiv/data/2017_summary-global-hiv-epidemic.png Erişim tarihi: 26 Mart 2019.

2. Karaosmanoğlu H. HIV İnfeksiyonuna Cinsiyet Bazlı Bakıș: Kadın ve HIV. FLORA 2018;23(3):95-101

3. 90-90-90. An ambitious treatment target to help end the AIDS epidemic [İnternet]. Geneva: Joint United Nations Programme on HIV/AIDS (UNAIDS). http://www.unaids.org/sites/ default/files/media_asset/90-90-90_en_0.pdf Erișim tarihi: 26 Mart 2019.

4. Gökengin D. Türkiye'de HIV İnfeksiyonu: Hedefe Ne Kadar Yakıniz? Klimik Derg 2018; 31(1): 4-10.

5. http://www.unaids.org/sites/default/files/media_asset/20160318_ten_targets_en.pdf Erișim tarihi: 26 Mart 2019

6. AIDS (2007) epidemic update. Geneva: UNAIDS. http://www.unaids.org/en/KnowledgeCentre/HIVData/EpiUpdate/EpiUpdArchive/2007/default.asp Erişim tarihi: 24 Mart 2019

7. Aslan FG, Altındiş M. HIV'in Güncel tanı algoritmi ve gelișen korunma yöntemleri. Türk Mikrobiyol Cem Derg 2017;47(2):47-60.

8. Sucaklı MB. Türkiye'de HIV/AIDS Epidemiyolojisi Ve Kontrol Programı, Klinik HIV/AIDS Sempozyumu, Antakya, 26-27 Kastm 2011

9. Centers for Disease Control and Prevention and Association of Public Health Laboratories. Laboratory testing for the diagnosis of HIV infection: updated recommendations. 2014. http://stacks.cdc.gov/view/cdc/23447. Erişim tarihi: 26 Mart 2019

10. Sayan, M., Hinçal, E., Şanlıdă̆ T, Kaymakamzade B, Tijjani Sa’ad F, Baba IA. Dynamics of HIV/AIDS in Turkey from 1985 to 2016 Qual Quant 2018;52(Suppl 1): 711. https://doi. org/10.1007/s11135-017-0648-7
11. Demir T. HIV tanı algoritmasında güncel gelişmeler, XXXVII. Türk Mikrobiyoloji Kongresi Kitabl, s.147, Antalya (2016)

12. Tümer A. HIV/AIDS Epidemiyolojisi ve korunma, Hacettepe Üniversitesi HIV/AIDS tedavi ve araştırma merkezi yayın. http://www.hatam.hacettepe.edu.tr/aids.shtml Erişim tarihi: 26 Mart 2019

13. Gökengin D, Oprea C, Uysal S, Begovac J. The growing HIV epidemic in Central Europe: a neglected issue? J Virus Erad 2016; 2(3): 156-61.

14. Erdinç FŞ, Dokuzoğuz B, Unal S, et al. Changing trends in the epidemiology of Turkey. In: 30th IUSTI Europe Conference (15-17 September 2016, Budapest, Hungary) Abstract Book. UK: International Union Against Sexually Transmitted Infections, 2016: 115-6.

15. Gilad J, Walfisch A, Borer A, Schlaeffer F. Gender differences and sex-specific manifestations associated with human immunodeficiency virus infection in women. Eur J Obstet Gynecol Reprod Biol 2003; 109: 199- 205.

16. Shapiro MF, Morton SC, McCaffrey DF, Senterfitt JW, Fleishman JA, Perlman JF, et al. Variations in the care of HIV-infected adults in the United States: results from the HIV Cost and Services Utilization Study. J Am Med Assoc 1999; 281:2305- 2315.

17. Acar A, Kemahli S, Altunay H, Kosan E, Oncul O, Gorenek L, Cavuslu S. HBV, HCV and HIV seroprevalence among blood donors in Istanbul, Turkey: how effective are the changes in the national blood transfusion policies? Braz J Infect Dis 2010;14:41-46. 